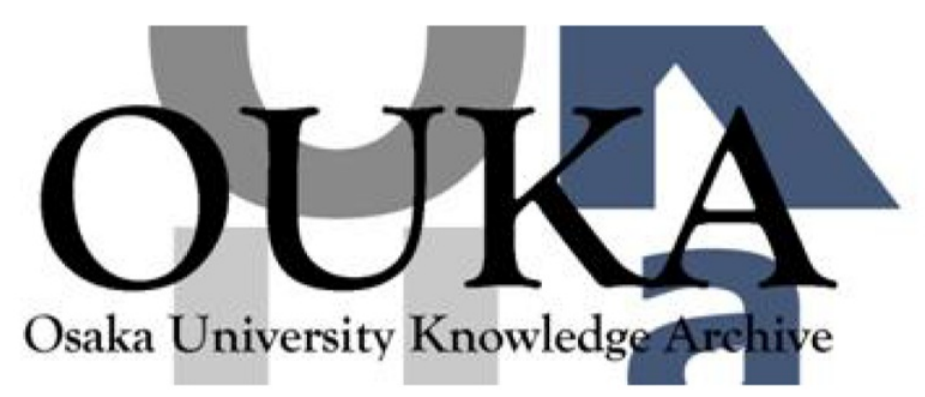

\begin{tabular}{|c|l|}
\hline Title & $\begin{array}{l}\text { On the Parallelism Between Sentence-Formation } \\
\text { and Text-Formation with Special Reference to } \\
\text { Coordinate Structures }\end{array}$ \\
\hline Author(s) & Okada, Sadayuki \\
\hline Citation & $\begin{array}{l}\text { OUPEL(Osaka University Papers in English } \\
\text { Linguistics). 1 p.37-p.59 }\end{array}$ \\
\hline Issue Date & $1993-07$ \\
\hline oaire:version & VoR \\
\hline URL & https://doi.org/10.18910/72963 \\
\hline rights & \\
\hline Note & \\
\hline
\end{tabular}

Osaka University Knowledge Archive : OUKA

https://ir. Library. osaka-u. ac. jp/

Osaka University 


\section{ON THE PARALLELISM BETWEEN SENTENCE-FORMATION AND TEXT-FORMATION WITH SPECIAL REFERENCE TO COORDINATE STRUCTURES*}

In the early days of transformational grammar, Ross (1967) noticed several peculiarities in the formation of long distance dependencies, which he accounted for by means of formal syntactic constraints on movement transformations. One of these, known as the coordinate structure constraint, banned extraction from coordinate structures; however, an exception was allowed for across-theboard movement that affected all conjuncts. While many of Ross's constraints have been softened over the years, his statements about coordinate structures are still thought to be empirically impeccable, so that his approach has been incorporated into the basic axiomatizations of many syntactic theories, like GPSG (Gazdar 1981), GB (Goodall 1987), and LFG (Kaplan and Zaenen 1989). Counterexamples to Ross's constraints on extraction out of coordination have been pointed out, even by Ross himself, but these have usually been treated as limited sub-regularities that lie outside of the core phenomenon to which the generalization applies. We shall show that the set of counterexamples is much vaster than is generally assumed and that, to the degree that it is tenable, Ross's syntactic generalization about extraction from coordinate structures falls out from more general, overriding principles of textual coherence.

The principles of textual structure that we have in mind are not at all radical and are partly echoed in the works of such researchers as Beaugrande and Dressler (1981) and Longacre (1979). Basically, when a theme that is common throughout a sequence of sentences is first introduced, the beginning and the ending of the rheme must be strongly related to this theme, so that a kind of semantic closure is formed among the various components of the text. We maintain that the problem with many negative data that figure in discussions of extraction from coordinate structures is that they blatantly disregard one basic discourse constraint on conjunction: the above-described thematic closure that must obtain with a sequence of sentences constituting a text must also be present in any well-formed sequence of conjuncts.

In this paper we shall present several examples featuring acceptable, non-across-the-board extractions from coordinate structures. This accomplishes a negative task, in that it demonstrates the inadequacy of Ross's constraints and all modern derivatives thereof. As for the positive goals of this paper, however, we must delve into sensitive areas of semantic coherence, which frankly do not always seem amenable to investigation using the usual judgment elicitation techniques of generative grammar. Since intuitions about matters of coherence are difficult for speakers to access, we cannot expect a given individual to report trustworthy reactions on all occasions. However, in the social and physical sciences there is, needless to say, a method for extracting trustworthy generalizations from data of uneven quality. One has only to collect several people's reactions to a set of linguistic data and subject the results to statistical methods. Towards this end we have conducted a survey of native English speakers who rated the acceptability of twenty-eight utterances involving extractions from coordinate structures. Statistically significant differences in acceptability are detectable between examples with different levels of cross-conjunct coherence.

The raw data and statistical results are summarized in two appendices at the end of this paper. Sentences that were included in the survey are marked as such in the text. These are supplemented with additional data gleaned from the literature or else judged by native informants in the traditional manner, where deemed uncontroversial.

\footnotetext{
*This is a paper based on my presentation at the symposium entitled "Aspects of Functional Approaches to Grammar" presented at the 63rd general meeting of the English Literary Society of Japan, held at Meiji University, May 18-19, 1991. I would like to thank Michael $\mathrm{T}$. Wescoat for his patient cooperation and encouragement all through the course of this study. His suggestions were always invaluable to me. Stephen W. Horn significantly improved the exposition and style of this text, and Everdyn A. Wescoat provided many further stylistic refinements. To both of them I acknowledge a debt of gratitude. My thanks also go to Ikuhiro Tamori and Hideo Tominaga of Kobe Shoka Daigaku (Kobe University of Commerce), whose cooperation was very helpful in the questionnaire I carried out as a part of this study. Finally, I would like to express my gratitude to all of the individuals who kindly took the time to fill out and return my questionnaires. Responsibility for any remaining deficiencies in this paper is, of course, my own.
} 
After investigating the problem of sentence-level coherence with regard to extraction phenomena from coordinate structures of various types, we will turn briefly to a wider perspective of text-level coherence. As we proposed earlier, these two levels of textual formation have much in common and can be treated in a parallel manner. The latter part of this paper is dedicated to verifying this assumption. In the course of our argument we will adopt a schema for the sake of convenience and apply this graphic form to the analysis of both of the two different levels of textual fragments in order to show the similarities discernible between them.

In the manner outlined above we hope to achieve a two-fold aim: to present a more empirically adequate picture of English extraction constructions such as relative clauses in their interaction with coordinate structures and also to show, in the process, that notions of textual organization can be profitably projected down to sentence-level in order to supplement syntactic mechanisms.

\section{Sentence-level Phenomena}

We start our argument with a consideration of some violations of the COORDINATE STRUCTURE CONSTRAINT (CSC) with regard to relative clause formation. It will be shown that these should be dealt with through a semantico-functional approach. We then move on to subject-object asymmetries in ACROSS-THE-BOARD (ATB) extraction, which are also hard to explain without consideration of semantic relatedness within coordinate structures. Finally, we will examine some more complex cases of scenario-type coordinate structures and then argue for the reduction of all these cases to a functional constraint based on a claim due to Kuno (1976).

\subsection{Violations of the Coordinate Structure Constraint}

In positing the CSC and a class of ATB exceptions to it, Ross made a strong claim about syntactic parallelism in extraction from coordinate structures. The CSC and ATB exceptions are expressed as follows:

(1) a. Coordinate Structure Constraint

In a coordinate structure, no conjunct may be moved, nor may any element contained in a conjunct be moved out of that conjunct. ${ }^{1}$

(Ross 1986:98-99)

\section{b. ACROSS-THE-BOARD EXCEPTIONS}

There is an important class of rules to which the above does not apply. These are rule schemata which move a constituent out of all conjuncts of a coordinate structure.

(ibid.:107)

This constraint and its exceptions introduced above predict that extraction from a conjunct is licensed only when parallel extractions occur in all sister conjuncts. ${ }^{2}$ However, the following data counterexemplify this prediction:

\footnotetext{
IThe CSC, as formulated in (1a), was intended to rule out, among other things, structures like those below, where the whole of a conjunct has been extracted.

(i) **This is the chair that John sat between the table and $e$.

(ii) **This is the table that John sat between $e$ and the chair.

Such forms as these are irredeemably ungrammatical in a way that the other presumed infelicities which the CSC was intended to address are not. Consequently, it seems intuitively quite satisfying to follow Grosu (1973) and Gundel (1974) in supposing that the type of ill-formedness found in (i) and (ii) should be ruled out with some special mechanism separate from any statements one might make pertaining to extractions of subparts of conjuncts. Basically, all conjuncts in a coordinate structure should have a non-null phonetic realization. We will have nothing more to say about data like (i) and (ii), concentrating instead on the other sort of data that the CSC targets, i.e., extraction not of but from conjuncts. As already indicated, we shall endeavor to show that extraction of the latter kind is not subject to any syntactic constraint along the lines of the CSC.

${ }^{2} \mathrm{~A}$ word of warning is in order about possible confusions regarding sources of ungrammaticality among coordinate structures that have undergone extraction. Not all such unacceptability is attributable to the CSC. For instance, the unacceptability of the following sentence which involves an extraction out of a complex NP is not to be treated as a CSC violation, but as a violation of the Complex NP constraint:
}

(i) *This is the man whom John saw $e$ and knew the woman who got married to $e$.

The unacceptability of this sentence is due to that of the following sentence:

(ii) *This is the man whom John knew the woman who got married to $e$.

Here we are concerned only with those cases where the extraction of an element is in itself acceptable, that is to say, where the host conjunct does not constitute an opaque domain for extraction, such as a complex NP or a wh-island. 
(2) SENTENCE CONJUNCTIONS

a. ?This is the building that got banged up in the earthquake, and then the resultant damage cost $\$ 50,000$ to repair. [survey]

b. This is a kind of beer that you can drink three bottles of, and still your blood alcohol level won't rise over the legal limit.

[survey]

c. ??Here is the whiskey that we went to the store and Mike bought. (Kuno 1976:442)

(where Mike is included in the referent of we)

(3) VP CONJUNCTIONS

a. This is the brandy that John went to the store and bought. [survey]

b. This is the diamond ring that Mary sold and then used the profits to buy a car.

[survey]

c. This is the kind of organ that Mary bought and thereby angered her husband.

(Kuno 1976:420)

(4) AP CONJUNCTION

There is an important area that John is deficient in and therefore unemployable; it's marketing.

[survey]

(5) NP CONJUNCTIONS

a. The futures market is something that you need a good understanding of and a lot of luck, to use it to your advantage.

[survey]

b. These are the reports that the government regulates the appearance of but not their contents.

(6) PP CONJUNCTION

?This is the building that we found ants on the roof of and also in the basement. [survey]

(7) ADJUNCT EXTRACTIONS

a. That is the place where John got into a bad accident and then the ambulance didn't arrive for an hour.

[survey]

b. That is the intersection where John ran over a pedestrian and then fled the scene of the crime.

[survey]

A simple constraint that prohibits non-across-the-board extraction out of a coordinate structure is hard to defend in the face of these examples.

1.1.1 The Purpose Clause Analysis. Ross himself recognized that there are exceptions to his CSC, such as (3a). He tried to explain the exceptions by assuming that typical violations of the CSC are found in cases where the conjuncts are connected through the interpretation of 'purpose.' He didn't regard (3a) as a true coordinate structure, but as a special case equivalent to the purpose clause construction This is the brandy that John went to the store in order to buy. Such a reanalysis can work only in the case of VP coordination, since the right hand conjunct has to be compatible with infinitival to. Hence, this approach is doomed to failure in the case of coordinate structures of other syntactic categories. There are other researchers who regard the exceptional cases as false coordinations-Goldsmith (1985), Pesetsky (1982), Sag, Gazdar, Wasow, and Weisler (1985), and so on-but their accounts are concerned only with VP coordination, and it is doubtful that their reasoning may be applied to all the other cases. 
1.1.2 The Thematic Constraint. The CSC violations listed in (2)-(7) are acceptable because there is some kind of semantic relatedness connecting the conjuncts and the antecedents in question. A possible way to model this semantic connexity may be found in a functional explanation based on the work of Kuno (1976).

\section{(8) The Thematic Constraint on Relative Clauses}

A relative clause must be a statement about its head noun. ${ }^{3}$

(Kuno 1976:420)

This is, as Kuno himself admits, nothing more than an ordinary statement about relatives. Still it seems to be a useful principle to solve the problem at hand. In all of the cases where the sentence is judged to be acceptable, the conjuncts are closely connected through one of various possible interpretations: 'purpose,' e.g., (2c), (3a), (3b); 'cause and effect,' e.g., (2a), (3c), (4); 'supplementing,' e.g., (5a), (6); 'against usual expectation,' e.g., (2b), (5b); and 'location,' e.g., (7a), (7b). So in each case the conjunct which is not related to the antecedent by way of a syntactic gap also contributes to the statement about the antecedent. Contrast the acceptable examples above with those below, which exhibit the same syntactic form-a gap in one conjunct and none in the other-but which lack semantic connexity between the two conjuncts and also between the gapless conjunct and the head noun. ${ }^{4}$

(9) a. SENTENCE CONJUNCTION

*This is the man that John saw and Bill hit Mary.

[survey]

b. VP CONJUNCTION

*This is the sandwich that John made and ate an apple.

[survey, cf. Lakoff's (1986:159) example (25)]

c. AP CONJUNCTION

*This is the person that John is afraid of and sorry about the accident. [survey]

d. NP CONJUNCTION

*This is the water that John bought a quart of milk and a gallon of.

[survey, cf. Lakoff's (1986:161) example (29)]

e. PP CONJUNCTION

*This is the problem that John complained about and about the Gulf Crisis. [survey]

f. ADJUNCT EXTRACTION

*That is the place where John went and Bill met Mary in New York.

[survey]

We cannot expect a coherent statement about the head noun from this kind of conjunct combination. The differences in acceptability between examples (2)-(7) and those in (9) are clearly supported by the results of the statistical examination set out in appendix 2 . For example, both (2a) and (9a) involve sentence conjunction, and the former is judged to be significantly more acceptable. Although (2a) is not universally accepted, in the survey this prediction is corroborated, since the difference of mean values assigned to the two sentences is significant at the level of 0.001 , the strictest criterion in common use. The same level of significance is found for all the other combinations of sentences from (2)-(7) and (9) involving like categories in the respective coordinate structures.

To support the present claim about semantic connexity between all conjuncts and the head noun, we will apply the What about $X$ ? test. In response to the question What about $X$ ? one has to present a statement concerning $X$, and if something irrelevant to $X$ is involved in the answer, the exchange turns out to be unnatural. In the following application of the test, $X$ corresponds to the NP used as the antecedent, and the answer corresponds to the expression used in the relative clause.

(10) What about the building?

\footnotetext{
${ }^{3}$ Gundel (1974) presents a similar idea.

${ }^{4}$ Our concern lies in the acceptability of sentences, not with grammaticality. The sentences with asterisks are grammatical, but their acceptability is low in degree because of the lack of semantic relatedness. Acceptable and unacceptable examples do not differ in syntactic properties, but in semantic coherence.
} 
It got banged up in the earthquake and the resultant damage cost $\$ 50,000$ to repair.

(11) What about this beer?

You can drink three bottles of it, and still your blood alcohol level won't rise over the legal limit.

[cf. (2b)]

(12) What about the brandy?

John went to the store and bought it.

(13) What about marketing?

John is deficient in it and therefore unemployable.

[cf. (4)]

(14) What about the futures market?

You need a good understanding of it and a lot of luck, to use it to your advantage.

(15) What about this house?

We found ants on the roof of it and also in the basement.

(16) What about the intersection?

John ran over a pedestrian there and then fled the scene of the crime.

[cf. $(7 b)]$

(17) What about the man?

*John met him and Bill hit Mary.

[cf. (9a)]

(18) What about the sandwich?

*John made it and ate an apple.

(19) What about this person?

*John is afraid of him and sorry about the accident.

(20) What about water?

*John bought a quart of milk and a gallon of it.

(21) What about the problem?

*John complained about it and about the Gulf Crisis.

(22) What about the place?

*John went there and Bill met Mary in New York.

The judgments in these tests parallel those of the corresponding relative clause examples. Other constructions which consist of a topic (theme) and a comment about it (rheme), such as the as for $X$ construction, the cleft construction, and topicalization, yield identical results. Here we will restrict ourselves to citing only examples of the $i t$-cleft construction.

(23) It was this building that got banged up in the earthquake, and the resultant damage cost $\$ 50,000$ to repair. [cf. (2a) and (10)]

(24) It was the brandy that John went to the store and bought. [cf. (3a) and (12)] 
(25) It is marketing skill that John is deficient in and therefore unemployable.

[cf. (4) and (13)]

(26) It is the futures market that you need a good understanding of and a lot of luck, to use it to your advantage.

[cf. (5a) and (14)]

(27) It was John's house that we found ants on the roof of and also in the basement.

[cf. (6) and (15)]

(28) *It was this person that John met and Bill hit Mary.

[cf. (9a) and (17)]

(29) * It was the sandwich that John made and ate an apple.

[cf. (9b) and (18)]

(30) *It is this man that John is afraid of and sorry about the accident.

[cf. (9c) and (19)]

(31) *It was water that John bought a quart of milk and a gallon of.

[cf. (9d) and (20)]

(32) *It was the problem that John complained about and about the Gulf Crisis. [cf. (9e) and $(21)]$

For the sake of convenience, now we will devise some schemata to indicate the relations between the antecedent and the conjuncts. We shall employ graphs of the following type:

(33) This is the brandy that John went to the store and bought.

$$
[=(3 a)]
$$

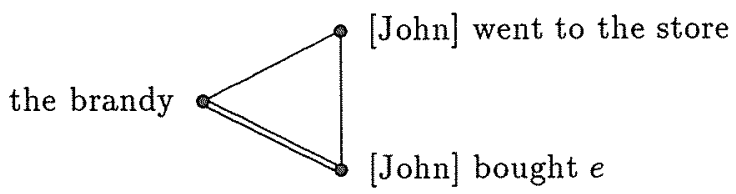

The main concept in the relative clause, i.e., the antecedent, is on the left and is connected with the host conjunct by a double line which indicates the syntactic relation of a gap. Single lines represent the semantic relations of the gapless conjunct with the antecedent and also with the host conjunct. In order to make these graphs more readable, any residue of the relative clause not contained in the conjuncts of the coordinate structure is written out in square brackets. ${ }^{5}$ Parenthesized material is occasionally provided to remind the reader of a given NP's reference.

(34) ?This is the building that got banged up in the earthquake, and then the resultant damage cost $\$ 50,000$ to repair.

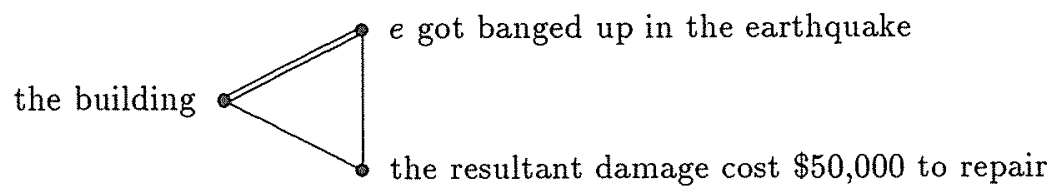

(35) There is an important area that John is deficient in and therefore unemployable: it's marketing.

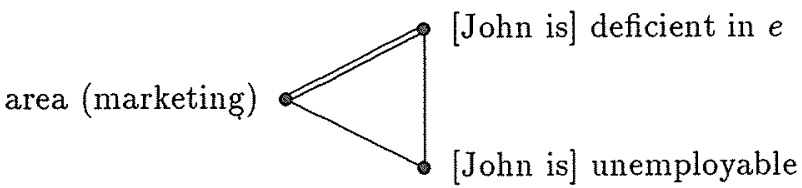

\footnotetext{
${ }^{5}$ The residue within square brackets is distributed to each of the conjuncts in the schema, but this doesn't mean coordinate structures consisting of VPs, NPs, or any other categories are generated through the application of conjunction reduction. This distribution of information is only for the sake of convenience, and nothing will follow from this schematic form.
} 
(36) The futures market is something that you need a good understanding of and a lot of luck, to use it to your advantage.

something (the futures market)

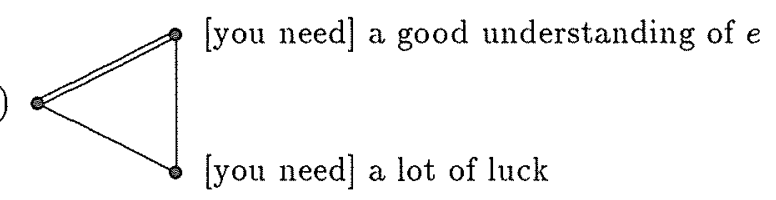

(37) ?This is the building that we found ants on the roof of and also in the basement. $[=(6)]$

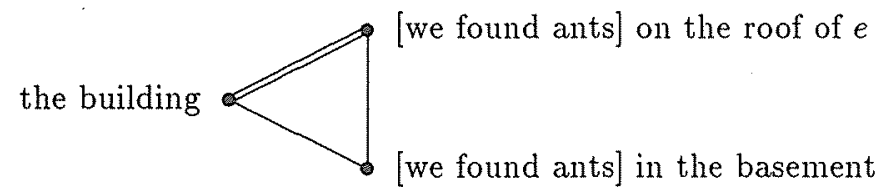

(38) That is the intersection where John ran over a pedestrian and then fled the scene of the crime.

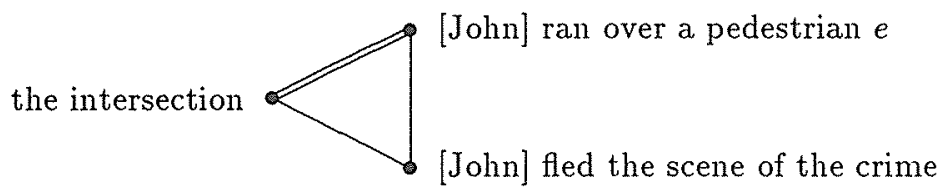

As for the semantic relations between the antecedent and the gapless conjunct, we can describe them in the following way: the store John went to in (33) was the place where the brandy was sold; in (34), the damage that amounted to $\$ 50,000$ was that of the building in the position of the antecedent; in (35), marketing is the area where John shows himself to be unemployable; a lot of luck is needed in the field of the futures market in (36); the basement in (37) is that of the building which is the antecedent; and the scene of the crime in (38) was the intersection itself.

When it comes to the second type of semantic relation, that between the conjuncts themselves, those items that come right after the coordinating word and (such as the expressions then, therefore, thereby, still, and also) are good indicators. They express the relations of 'succession of events,' 'cause and effect,' 'against expectation,' 'supplementing,' and so forth, that exist between the conjuncts.

On the other hand, in all the cases below, single lines representing semantic relatedness are lacking, and the gapless conjunct has no relation to maintain with the antecedent. These schemata make it plain that the conjunct in question makes no contribution to the statement about the head noun.

(39) *This is the man that John saw and Bill hit Mary.

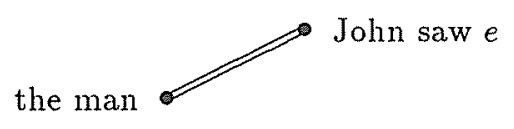

- Bill hit Mary

(40) *This is the sandwich that John made and ate an apple.

$[=(9 b)]$

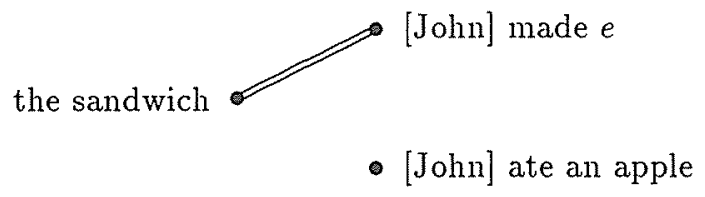


(41) *This is the person that John is afraid of and sorry about the accident.

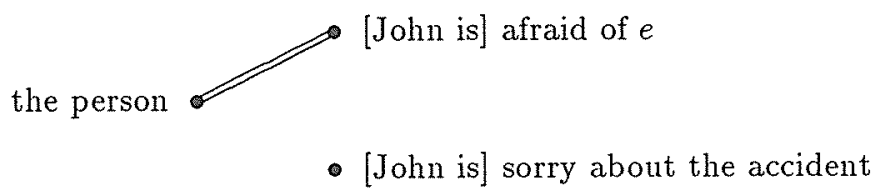

(42) *This is the water that John bought a quart of milk and a gallon of.

- [John bought] a quart of milk

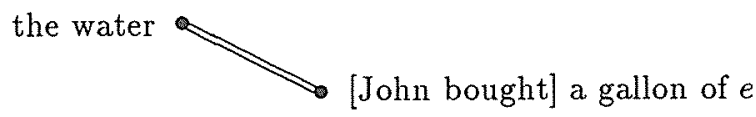

(43) *This is the problem that John complained about and about the Gulf Crisis. $\quad[=(9 \mathrm{e})]$

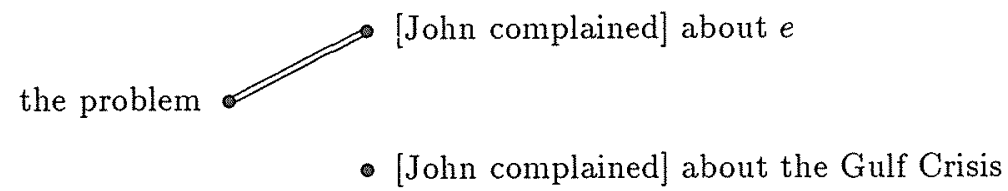

(44) *That is the place where John went and Bill met Mary in New York.

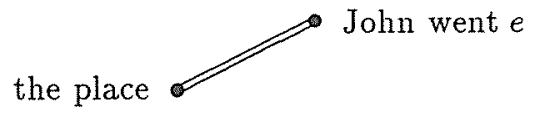

- Bill met Mary in New York

With reference to these schemata, we will look more deeply into the problems concerning relative constructions involving coordinate structures.

\subsection{Subject-Object Asymmetry}

Williams (1978), Gazdar (1981), Pesetsky (1982), and Goodall (1987), among others, maintain that there is a general syntactic condition on ATB extraction from coordinate structures which concerns the grammatical function of the gaps. ${ }^{6}$ Their arguments are mainly based on the sort of contrasts shown below.

(45) Subject-Subject

a. I know the man who ran the race and won the first prize.

[survey]

b. This is the man who saw John and hit Bill.

(46) OBJECT-OBJECT

a. This is the book which John wrote and Bill illustrated.

b. This is the man who John saw and Mary kissed.

[survey]

(47) MIXED

a. ??This is the man that saw John and Bill hit.

(Subject-Object) [survey]

b. *This is the man who John knew and hated Mary.

(Object-Subject) [survey]

${ }^{6}$ Williams (1978) tries to deal with the problems of coordinate structures with the idea of factorization, Gazdar (1981) with a treatment that views subject relatives as a special case with the category VP, Pesetsky (1982) with his path containment condition (PCC), and Goodall (1987) with the binding conditions. 
When an NP which assigned the same grammatical function in each conjunct is extracted, the sentence is assumed to be grammatical. This is in contrast to cases like (47a) and (47b), where the grammatical functions of the extracted NP are not identical and where the structure is therefore assumed to be ungrammatical. This much is supported by the results of the questionnaire carried out as a part of this study. In appendix 2, there is no significant difference in acceptability between (45a) and (46b), and more importantly, their mean values of acceptability are high, as recorded in appendix 1. When it comes to the sentences in (47), where the grammatical functions of the gaps are different, acceptability is significantly lower. But it is not always true that coordinate structures with mixed-function gaps are unacceptable. Anderson (1983) indicates that the following sentences, which are rich in contextual information, are grammatical, contrary to the prediction of the usual formalistic approaches:

(48) SuBjeCt-OBJECT

a. Caruso was a tenor who sang like an angel and audiences adored.

b. We are trying to fire the chairman who is terribly inflexible and committee members strongly dislike.

[survey]

(49) OBJECT-SUBJECT

a. Nancy was wearing a gown that Galanos designed and cost over $\$ 5,000$. [survey]

b. We went to see a movie which the critics praised but was too violent for my taste. [survey]

c. That's the candidate who the unions endorsed and was the overwhelming favorite of the Democrats.

Intuitive judgements indicating differences in acceptability between (47a) and (48), where the extraction pattern of subject-object is involved, and between (47b) and (49), where the pattern of object-subject extraction is in question, are again corroborated by our statistics. Examples cited in (48) and (49) are much better than those in (47). In the face of these counterexamples, the oddness of the examples in (47) seems to be attributable, again, to the low degree of semantic association between the conjuncts.

When we look into the problem more closely, we find a difference in acceptability among examples, which turns out to make an interesting contribution to the present analysis. First of all, Goodall (1987) admits that (47a) is better than (47b) for some native speakers. This point is also corroborated by appendix 2 . From the viewpoint of parsing, there is a difference between these two sentences in the ease of locating the expected gaps. That is to say, in (47a), there is no great effort needed to identify the gaps in the subject and the object positions, because a sentence has to have a subject, and a transitive verb like hit has to have an object. On the other hand, in (47b), there is a structural ambiguity which brings about some processing effort: the second gap in the subject position is hard to identify, because this position could be filled by the subject of the first conjunct John rather than by the antecedent the man. The expected reading is suspended by the possible reading of VP conjunction inside the relative clause. In (49), where the same kind of configuration is used, no such ambiguity arises in any of the three cases, because the VP-conjunction reading encounters some semantic or syntactic anomaly. Hence, the high acceptability of these examples.

Taking into consideration all the observations above, let us consider the difference in the degree of acceptability of the following examples:

(50) *This is the man who John knew and hated Mary.

$[=(47 \mathrm{~b})$, survey $]$

(51) We went to see a movie which the critics praised but was too violent for my taste. $[=(49 \mathrm{~b})$, survey]

(52) ?This is the movie that John's son saw and was made by a French director. [survey]

In comparison with (50), both (51) and (52) are easier to process, because the second gap in the subject position is unambiguously filled by the head noun movie. And yet, there is a difference in acceptability between (51) and (52), the former being more acceptable than the latter. We submit that this is because the semantic relatedness between the conjuncts is richer in the former example. 
The speaker of (51) complains about the fact that the movie, which was praised by critics and which, of course, should have been great fun, was, contrary to expectation, too violent. The whole situation described in this sentence is something that might happen at any time and is therefore easy to imagine.

In contrast, in (52), the fact of someone's watching a movie and the identity of the director of that movie are not so clearly connected. Of course, connections could be concocted to relate the conjuncts. Short of developing an elaborate scenario with unexpressed motivations, the most typical principles of semantic relatedness that could serve to establish connections are things like 'temporal sequence,' 'cause and effect,' 'intentionality,' or 'enablement.' None of these seems applicable in this case: the order of the conjuncts rules out both temporal sequence and cause and effect, since movies can't be viewed before they are made and the act of viewing can't cause a movie to be created. An intentional reading is equally impossible, because viewing a movie is no means to the end of its being made. So any semantic relatedness between the conjuncts in (52) is, on the whole, not obvious. It is not so strange, therefore, to find a difference in acceptability between (51) and (52). Again, in appendix 2, the differences among the three sentences in question- $-(50)$, (51), and (52) - are cited, and the results tell us that each of them is significantly different from the other two. So it seems perfectly justifiable to assign three different acceptability markers to these three sentences.

The same kind of reasoning can apply to the following set of examples as well:

(53) a. This is the paper that Jolın sent to a million different journals and was finally accepted by the Albanian Linguistics Society Newsletter.

b. ??This is the paper that someone wrote and appeared in a journal published last week.

By now, it seems to be clear that the syntactic approaches to the apparent subject-object asymmetries should be replaced by a functional approach dealing with the semantic coherence between conjuncts. Using the schemata we adopted in the foregoing section, we can offer illustrations like the following:

(54) ??This is the man that saw John and Bill hit.

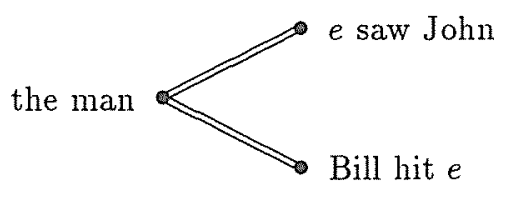

(55) We are trying to fire the chairman who is terribly inflexible and committee members strongly dislike.

$[=(48 \mathrm{~b})]$

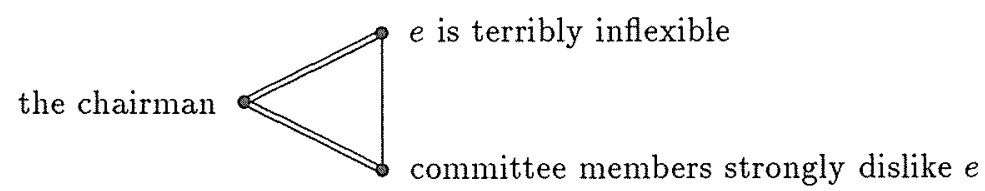

The conjuncts each have a gap, so the functional requirement of 'a statement about the head noun' appears to be satisfied independently by each of the conjuncts, because they are connected with the head noun by means of this syntactic relation. But this is not enough. Without the vertical line, which indicates the existence of some rich semantic relatedness between the conjuncts, the acceptability of the sentences in question diminishes. In the case of (55), we can assume the semantic relation of 'cause and effect' between the conjuncts, but in the case of (54), no such strong relation can be detected between the conjuncts. The evidence leads us to the view that the full set of conjuncts, taken as a whole, have to form a coherent statement about the head noun. 


\subsection{Identical Grammatical Functions}

One more problem still remains to be introduced. At the outset of the preceding subsection, we saw that when gaps are identical in grammatical function, the sentences are found to be highly acceptable. This appears to be the case even when there is little semantic coherence between the conjuncts, as (45b) and (46b) illustrate. It is true that the functional identity of gaps will alleviate the processing effort involved in ATB extraction-perhaps some kind of structural parallelism is involved here - but still, semantic relatedness also plays a role in deciding the acceptability of these sentences. Consider the following:

(56) This is the man who saw John and hit Bill.

$[=(45 \mathrm{~b})]$

(57) a. ??This is the man who saw John and hits Bill.

b. Yesterday I met someone who had an accident as a child and is still troubled with a limp as a result of it.

In cases such as (56) and (57a), where there is little semantic relatedness, the whole sentence becomes less acceptable when the tenses of the conjuncts differ. But this apparent shortcoming may be remedied by a richer context, as in (57b). This clearly shows that even in cases of functionally identical gaps, semantic relatedness counts. Also the difference between (56) and (57a) suggests that even when there seems to be no semantic relatedness, the identity of tense helps to connect the conjuncts, because the two events described by the verbs in each conjunct are recognized as happening in the same 'past' time. This factor leads to the possible interpretation of 'successive actions,' 'cause and effect,' or some other such relation. ${ }^{\text {? }}$

Another set of examples that demonstrate a similar point, this time with the aspectual form of the present perfect, is cited below.

(58) a. This is the wine that John went to the store and bought.

b. *This is the wine that John went to the store and has bought.

(Ross 1986)

c. This is the wine that John went to the store one day and has bought ever since because of its nice bouquet.

We can also observe the importance of coherence among the conjuncts in examples of ATB extractions inside VP conjunctions.

(59) a. This is the dress that Mary took out from the closet, tried on, put back, took out again, and then put on.

b. *This is the man that John talked to, met on the street, spoke ill of, hit, and wanted to see again.

(60) a. This is the man who went to the store, bought the wine, drove home, and had the wine with dinner.

b. ??This is the man that hit Bill, saw Mary, talked to John, hated Harry, and knew Mike.

It is natural to have multiple conjuncts describing events as a recognizable temporal sequence, as in (59a) and (60a), while it is extremely awkward to arrange VP's at random within a relative, as in $(59 \mathrm{~b})$ and $(60 \mathrm{~b})$. In (59), all the gaps have the identical grammatical function of object, and in (60), of subject, but this parallelism itself is once again not enough. Schematically, we can illustrate this as in the following:

\footnotetext{
${ }^{7}$ Sameness of grammatical functions and of tenses may be regarded as weak types of relatedness connecting the conjuncts, which help to promote the acceptability of sentences, but which, in isolation, cannot be the crucial factor of promotion.
} 
(61) This is the dress that Mary took out from the closet, tried on, put back, took out again, and then put on.

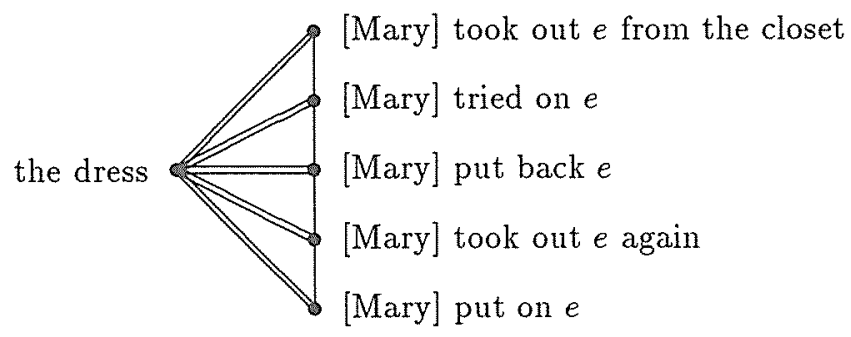

(62) *This is the man that John talked to, met on the street, spoke ill of, hit, and wanted to see again.

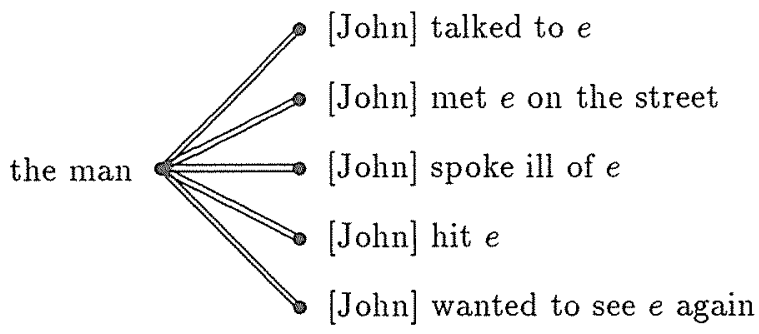

In these cases, all conjuncts have a double line connected with the head noun, because they each have a syntactic link due to the presence of a gap. But the semantic relatedness between the conjuncts, or the single vertical line designating, in these cases, a recognizable temporal sequence, is lacking in examples whose acceptability is low in degree.

Here we have found that in the case of ATB extractions, just as in the preceding cases, semantic relatedness between conjuncts is important and also that the identity of grammatical functions of gaps is not, in itself, sufficent means for determining the acceptability of a sentence.

\subsection{Multiple or Scenario-type Conjunction}

At the end of the previous subsection we saw some examples of multiple or scenario-type conjunction, first examined by Lakoff (1986). This also poses a serious problem for the CSC, because, as the following examples show, NPs may be freely extracted from any subset of the conjuncts:

(63) a. ?This is the wine that John went to the store, bought, drove home, had dinner, and then tasted.

[survey]

b. This is the kind of brandy that you can sip after dinner, watch TV for a while, sip some more of, work a bit, finish off, go to bed, and still feel fine in the morning.

(Lakoff 1986:153)

c. Sam is not the sort of guy you can just sit there, listen to, and not want to punch in the nose.

(Lakoff 1986:153)

d. This is the dress that she went to the closet, took out, tried on, put back, and took out again.

e. This is the jewel that John took a train, went all the way to Manhattan, and bought at Tiffany's.

f. This is the book that they called all over town, wrote letters to various wholesalers, eventually contacted the publisher, and still couldn't get a copy of.

For instance, in (63a), extraction occurs in the second and the final conjuncts; in (63d), it occurs in the second, the third, the fourth, and the final conjuncts; finally, in (63f), it is found only in the final conjunct.

It seems true, as Lakoff claimed, that we can freely extract an element from a scenario-type coordinate structure, but we must also note that the functional constraint on relative clauses is at work here in these examples. One thing which is really revealing is that when these scenario-like chains of behavior are cut off in the middle, the degree of acceptability varies. 
(64) a. This is the wine that John went to the store and bought.

b. ??This is the wine that John went to the store, bought, and drove home.

c. *This is the wine that John went to the store, bought, drove home, and had dinner.

d. ?This is the wine that John went to the store, bought, drove home, had dinner, and then tasted.

(65) a. This is the kind of brandy that you can sip after dinner.

b. ??This is the kind of brandy that you can sip after dinner, and watch TV for a while.

c. This is the kind of brandy that you can sip after dinner, watch TV for a while, and sip some more of.

d. ??This is the kind of brandy that you can sip after dinner, watch TV for a while, sip some more of, and go to bed.

e. This is the kind of brandy that you can sip after dinner, watch TV for a while, sip some more of, go to bed, and still feel fine in the morning.

In the series of examples in (64), as the gapless conjuncts increase in number, the resulting sentences appear to be damaged more and more seriously. And yet, the final conjunct, which has a gap and which is therefore directly related with the antecedent by way of this syntactic connection, is crucially responsible for saving the sentence from total unacceptability. The result of the calculation of significance in acceptability among the four sentences in (64) is illustrated in appendix 2. Although the difference between $(64 \mathrm{~b})$ and $(64 \mathrm{~d})$ is not statistically significant, all the other comparisons show the expected significant results. In example (65), the same tendency holds, but with one significant difference. As in (64), the conjuncts that rescue the whole sequence are those which are closely connected to the antecedent. The first and the third conjuncts have gaps and are connected through this syntactic relation. The crucial difference, however, is that the last conjucnt is connected through semantic relatedness only. What this suggests is that the last conjunct must be connected to the antecedent, be it through syntactic or semantic means, in order for the coordinate structure to be acceptable.

The following array of data leads us to a similar observation about the first conjunct in a coordinate structure:

(66) a. This is the brandy that John went out and bought at a liquor shop.

b. ??This is the brandy that John came home, went out again and bought at a liquor shop.

c. *This is the brandy that John left his office, came home, went out again, and bought at a liquor shop.

In the above sequence of data, the initial, felicitous coordinate structure is rendered progressively less acceptable by the addition of initial conjuncts that are neither syntactically nor semantically related to the antecedent. Thus, it may be seen that not only the last but also the first conjunct needs to be connected to the antecedent in order for the coordinate structure to pass muster.

The two foregoing observations constitute the core of our analysis of the conditions on extraction from coordinate structures. We find that the crucial factors are the first and the last conjuncts, which must be connected with the antecedent either syntactically (through a gap) or semantically (through semantic relatedness). The effect is that the sequence of conjuncts within the relative clause from first to last can, taken as a whole, be regarded as a statement about the antecedent.

Our specifically mentioning the semantic relatedness of the first conjunct to the antecedent may seem somewhat confusing in light of examples where the first conjunct taken by itself bears no obvious connection to the antecedent, such as the wine that John went to the store and... among other examples. But this matter will be clarified shortly.

The claim that the combination of conjuncts taken as a whole must constitute a statement about the antecedent is supported by the familiar What about $X$ ? test.

(67) What about this wine? 
a. John went to the store and bought it.

[cf. (63a) and (64)]

b. ??John went to the store, bought it, and drove home.

c. *John went to the store, bought it, drove home, and had dinner.

d. John went to the store, bought it, drove home, had dinner, and then tasted it.

(68) What about this brandy?

a. You can sip it after dinner.

[cf. (63b) and (65)]

b. ??You can sip it after dinner and watch TV for a while.

c. * You can sip it after dinner, watch TV for a while, and go to bed.

d. You can sip it after dinner, watch TV for a while, go to bed, and still feel fine in the morning.

(69) What about this brandy?

a. John went out and bought it at a liquor shop.

b. ??John came home, went out again, and bought it at a liquor shop.

c. *John left his office, came home, went out again, and bought it at a liquor shop.

$$
\text { [cf. }(66 \mathrm{c})]
$$

Our analysis of scenario-type conjunctions leads us to view the networks of syntactic and semantic relatedness underlying various of the data examined above in the fashion illustrated by the following schemata:

(70) This is the wine that John went to the store and bought.

$[=(64 a)$, survey $]$

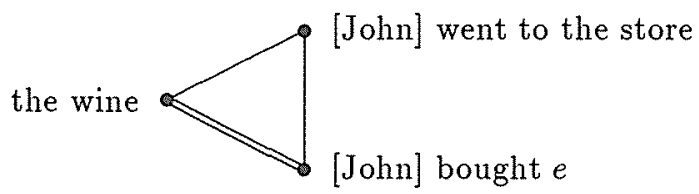

(71) *This is the wine that John went to the store, bought, drove home, and had dinner.

$[=(64 \mathrm{c})$, survey $]$

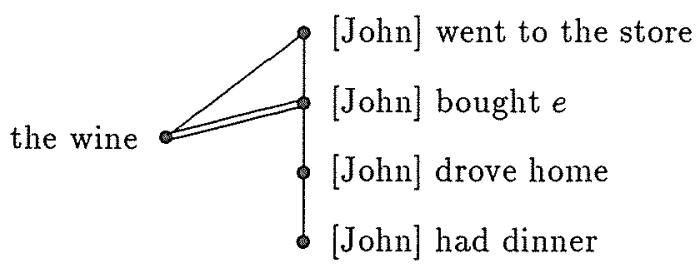

(72) ?This is the wine that John went to the store, bought, drove home, had dinner, and then tasted.

$[=(63 \mathrm{a})=(64 \mathrm{~d})$, survey $]$

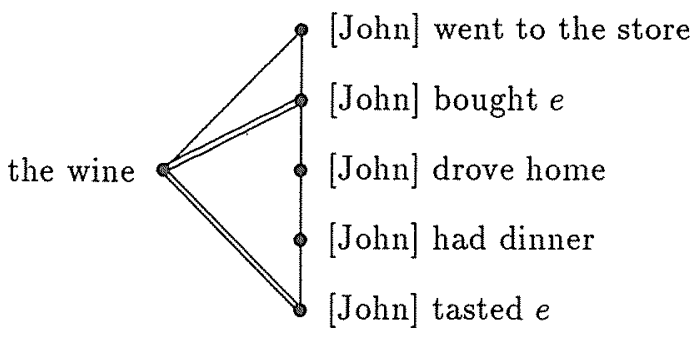


(73) ??This is the kind of brandy that you can sip after dinner, watch TV for a while, sip some more of, and go to bed.

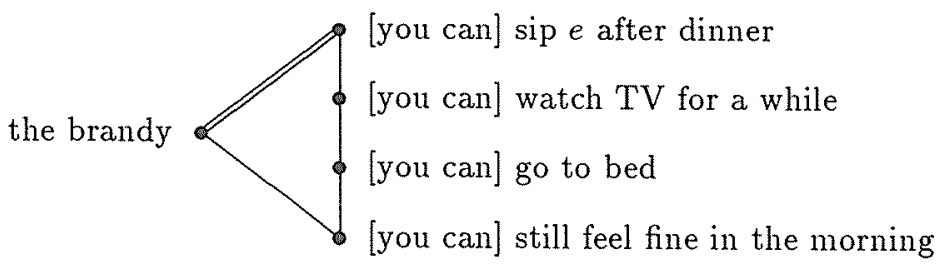

(74) *This is the brandy that John left his office, came home, went out again, and bought at a liquor shop.

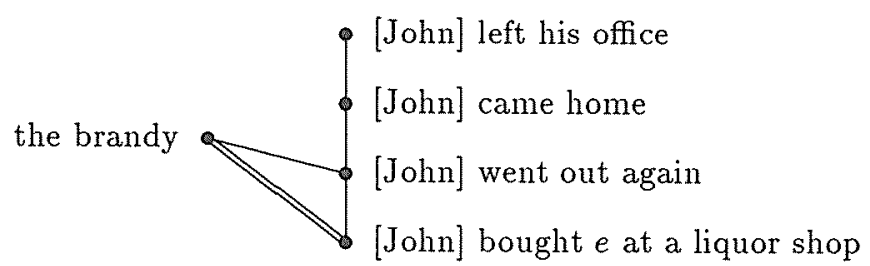

Let us now return to our claim that the crucial factors are the relatedness of the first and last conjuncts to the antecedent. Some of the cases examined may not seem at first glance to be in accord with this generalization. For example, if we consider (64a), graphed out in (70), This is the wine that John went to the store and bought, the first conjunct taken by itself has little to do with the antecedent. Hence, concerning our treatment of the graph in (70) (and for that matter, those in (71) and (72)), the justification for drawing a single line representing semantic relatedness between the first conjunct and the antecedent may not be immediately apparent. It is only after the second conjunct comes into play that we recognize the close relation of the first conjunct with the antecedent. It is by virtue of collocation that the second conjunct helps the first to maintain a semantic relation with the antecedent to form what we will call a CLOSURE. Viewed in this fashion, all of the acceptable coordinations exhibit connections between the first and last conjuncts and the antecedent, in accordance with our claim.

Now we can state a general constraint on the formation of schemata.

\section{(75) The Closure Constraint}

In order for a coordinate structure from which an element is extracted to be perceived as acceptable, the first and the last conjuncts must be related to the extracted element either through the syntactic means of a gap or through the semantic means of relatedness. Additionally, all of the conjuncts have to be semantically related to one another so that the conjunction as a whole forms a closure together with the extracted element.

The term 'closure' in this formulation refers to the closed area which is composed of lines, both double and single, in the schemata. In the acceptable cases there is a closed area including all the conjuncts and the antecedent, while in all the other cases there is some open space where the lines fail to enclose all of the conjuncts.

Incidentally, we have to remember that in English a relative clause has to have at least one gap which is identified with the antecedent. We have to add a simple syntactic constraint to this effect.

(76) The Gap Constraint

A relative clause in English has to have at least one gap identified with the antecedent.

There appears to be no particular constraint on where the gap occurs within the sequence of conjuncts. 


\subsection{Reduction of the Former Cases}

Looking back at the CSC violations discussed in sections 1.1 to 1.3 , we can reduce them to the present constraints by regarding them as abbreviated forms of complex, scenario-type coordinations containing the minimum number of conjuncts, i.e., two. As a matter of fact, looking back at the schemata presented in the preceding sections, we can see that they are closed when the sentence is acceptable and open at some point or other when unacceptable.

\section{(77) ATB extraction}

This is the whiskey that John bought at the store and tasted at dinner time.

\section{(78) TYPICAL VIOLATIONS OF THE CSC}

a. This is the kind of brandy that you can sip after dinner and still feel fine in the morning.

b. This is the whiskey that John went to the store and bought.

Since only two conjuncts are present and since both of these are required to bear some relation to the head noun, be it syntactic or semantic, it might appear that these minimal coordination examples are subject to a different, simpler constraint. However, the closure constraint can apply here equally well: it predicts that the first and last conjuncts will bear some relation to the head noun, and, in cases with only two conjuncts, this implies total involvement, i.e., both conjuncts are connected to the head. Furthermore, the closure constraint implies inter-conjunct semantic relatedness, and this requirement is visibly at work, even in minimal coordinations involving only two conjuncts.

That readily recognizable semantic relatedness among conjuncts is important can be detected from such examples as the following:

(79) a. This is the whiskey that John went to the store and bought.

b. *This is the wall that John went to the store and scratched.

In all of the foregoing cases, what is needed is semantic relatedness among conjuncts and a close relation between these conjuncts and the antecedent. In other words, a revised version of Kuno's functional constraint on relatives, presented here as the closure constraint, is a useful concept in dealing with the problems posed by coordinate structures inside relative clauses. It seems to be a hard task for a purely syntactic account to explain the difference in acceptability between the following:

(80) a. *This is the whiskey that John bought at the store, drove home, and had dinner.

b. This is the brandy that you can sip after dinner, work a bit, and still feel fine in the morning.

Both of the sentences have a gap in the first conjunct, with two gapless conjuncts following. Hence, they are not distinct from each other in their configurational properties. Furthermore, they include coordinate structures describing natural courses of events, which means that the traditional distinction of symmetric and asymmetric conjunctions is not the source of difficulty here. Still, they differ in acceptability. What we need to observe here is that one is semantically coherent-constituting a closure-as a statement about the antecedent, and that the other is not. ${ }^{8}$

\footnotetext{
${ }^{8}$ According to the closure constraint, examples such as $(2 \mathrm{a})$ and $(64 \mathrm{~d})$ are predicted to be perfectly acceptable. But the result of the questionnaire doesn't appear to confirm this view. This is probably due to a variety of extraneous factors. In the case of (2a), an informant suggested that the word bang carries with it some kind of association with 'a car crash' and that this image is not suitable for the description of a building destroyed in an earthquake. When compared with $(2 \mathrm{a}),(2 \mathrm{~b})$ is more natural and more acceptable because, as is pointed out again by some informants, the phrase used in this example would be highly appropriate as an advertisement for a beer company. When it comes to (64d), intonation plays a role in deciding its acceptability. That is to say, when the final conjunct is read with stress on it after a slight pause, the acceptability of this sentence is enhanced. No instructions about intonation were given in the questionmaire.
} 


\section{Text-level Phenomena}

Thus far, we have seen that our semantic and functional constraint is useful for the explanation of complex data regarding coordinate structures inside of relative clauses. A relative construction consists of an antecedent, which constitutes a theme about which a statement is made, plus a relative clause, which constitutes a rheme through which one can present the required statement. Now, the theme-rheme distinction is one of the basic concepts of functionalism in the Prague school and also among other researchers like Halliday and Kuno. The basic formation not only of sentences but of any coherent fragment of text is said to be divisible into the two parts of theme and rheme. Granting this, we can see that the observations we have made thus far about conjunction in sentences show some correspondence to the wider context of text formation. The aim of this section is to show that the theme-rheme combination in relative clauses is merely a reflection of that combination in larger texts and consequently that the principles of text-formation are mirrored in sentence-formation. This goal can be accomplished through the application to text fragments of the schematic structure we employed above.

\subsection{Direct Reference: An Analogy to ATB Extraction}

In the following examples, pronouns and epithets are used to refer to the main referent in the text. For instance, in (81a), grand-aunt is referred to in the next sentence with the epithet the poor old girl. Pronouns and epithets can be regarded as linguistic devices for unifying fragments of a text through the iterative use of a key item. This linguistic linkage is similar to ATB-type extraction, in that each of the fragments - corresponding to each of the conjuncts-employs a syntactic device to connect itself directly to the main referent, or the theme. In the case of ATB extractions, the covert device of gapping is adopted, while in the case of the following texts, the overt devices of epithet reference and pronominalization are used:

(81) a. I have been to see my grand-aunt. The poor old girl's getting very forgetful these days.

(Halliday and Hasan 1976:276)

b. The Rousseauist especially feels an inner kinship with Prometheus and other Titans. He is fascinated by any form of insurgency... He must show an elementary energy in his explosion against the established order and at the same time a boundless sympathy for the victims of it... Further the Rousseauist is ever ready to discover beauty of soul in anyone who is under the reprobation of society.

(Daneš 1974:119)

In the second example, Rousseauist reappears iteratively in the guise of pronouns. Needless to say, the use of pronouns in itself is not enough to guarantee the coherence of a text.

(82) John was a genius in his high school days. He will be married next week. His hobby is collecting old stamps. As a child, he often suffered from asthma.

All of the sentences in this example describe something about John, but it does not seem to be a natural text, because each of the sentences has little connection with the others. The syntactic devices for binding sentences together-pronouns and epithets-are not enough. This is just the same as in the case of ATB extractions, where semantic coherence between the conjuncts is crucial for deciding the acceptability of the whole sentence.

The difference in the naturalness of text formation recognized between (81b) and (82) can be expressed in schemata like these.

(83) [cf. (81b)]

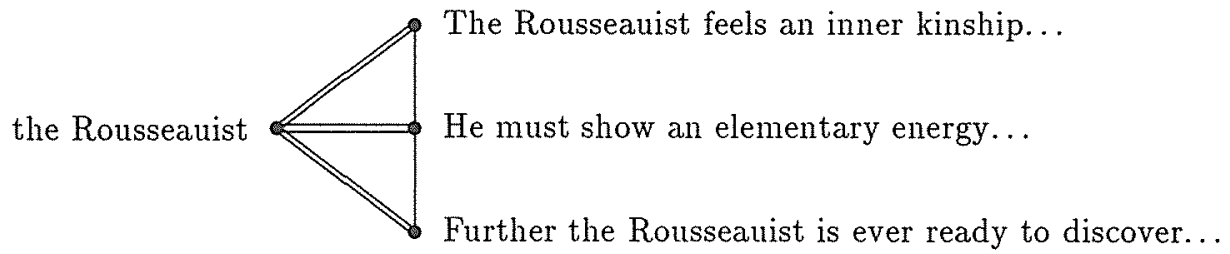


(84) [cf. (82)]

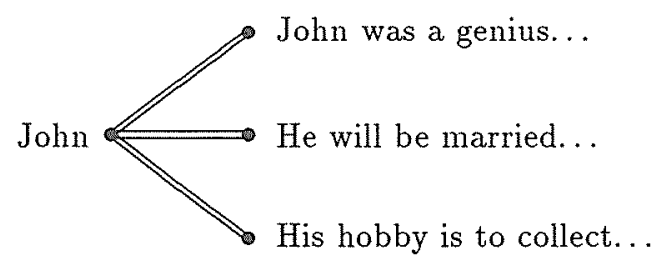

This time the double line designates the relation of direct reference by way of pronouns, epithets, or simple repetitions. The pronominal expressions considered in the present section are semantically bound to the theme on the left side of their schemata in the same fashion as were the gaps discussed in the preceding arguments with regard to relative constructions. These linkages are similar in that they both designate the relation of coreference, so there seems to be little problem about describing the gap-theme relation and the pronoun-theme relation in a similar way. The single line again indicates the existence of semantic relatedness, this time among fragments of a text. For example, each of the fragments of $(81 \mathrm{~b})$ has the common characteristic of 'describing the rebelliousness of Rousseauists,' and this characteristic plays the role of unifying these fragments into a coherent text. ${ }^{9}$

\subsection{Semantic Relatedness: An Analogy to CSC Violations}

In this and the next subsections, we will see a schematic correspondence between acceptable CSC violations (in subsections 1.1 and 1.4) and coherent text formation. We start our argument with a very simple and traditional type of text. When we consider the relation of simple sentences connected by and, we can see that the degree of relatedness between the sentences varies from example to example. Take, for instance, some extreme cases like the following:

(85) a. The film director owns a yacht, and doctors usually choose attractive mates.

b. The teacher came very late for the class, and the students were all already gone.

In the first example no specific motivation can be thought of for connecting the two sentences by and. A person's owning a yacht has nothing to do with proclivities of doctors for attractive mates. On the contrary, in the second case the referents of teacher and students are easily associated through our image of educational institutions, and the two sentences are related through the interpretation of 'cause and effect.'

Now let us apply the What about $X$ ? test to these examples.

(86) What about the film director?

*He owns a yacht and doctors usually choose attractive mates.

(87) What about doctors?

*The film director owns a yacht and they usually choose attractive mates. [cf. (85a)]

(88) What about the teacher?

He came very late for the class, and the students were all already gone.

(89) What about the students?

The teacher came very late for the class, and they were all already gone.

The answers derived from (85a) are totally inappropriate as responses to either the question about the film director or the one about doctors. This is similar to the examples where the CSC appears to hold or where one of the conjuncts which is gapless is totally irrelevant to the head noun. On the other hand, (85b) is similar to acceptable CSC violations like the following:

\footnotetext{
${ }^{9}$ In the case of a text formation, we don't always need a direct reference to the theme of the text. In other words, a double straight line is not necessarily required in a schema for text constructions. The syntactic constraint in (76) applies only to the sentence-level grammar of relative clause formation.
} 
(90) a. This is the store that John went to and bought the whiskey.

b. This is the whiskey that John went to the store and bought.

Going to the store and buying the whiskey are so closely related that either the store or the whiskey can be the antecedent (or the theme) of the relative clause. The same claim is true of (88) and (89), where both the teacher and the students can be the theme of the answer.

Another example, in a still larger context, can be found in an article entitled 'The Refrigerator' from a newpaper column (later published as a book).

(91) Would anyone want to buy two lambchops, the front quarter of a cooked chicken, half a package of green beans, a loaf of bread and five plastic containers, the contents of which are unknown to me?

A recent check reveals that we have these items in our freezer. They'd be a good buy for someone. The lambchops are circa 1976...

(Andrew Rooney, Mr. Rooney's Art of Living (Tokyo: Nan'un-do, 1986), 5)

The story begins with a question about the contents of the freezer, with no reference at all to the refrigerator itself. Still, because the theme of the piece is fixed immediately by its title 'The Refrigerator,' the question posed at the outset of the column proves to be a natural and witty comment perfectly relevant to the theme. Direct reference to the theme is delayed until the second paragraph, and so the first paragraph is connected to the theme only through the device of semantic relatedness. If we regard each of the two paragraphs as corresponding to the conjuncts in the case of the wine that John [went to the store] and [bought e], we can see an analogy between text formation and sentence-level grammar.

Schematically, our observations can be expressed as follows:

(92) $[=(85 \mathrm{a})]$

the film director He owns a yacht

- doctors usually choose attractive mates

(93) $[=(85 b)]$

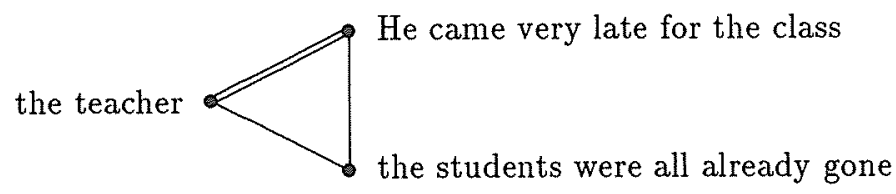

(94) $[=(91)]$

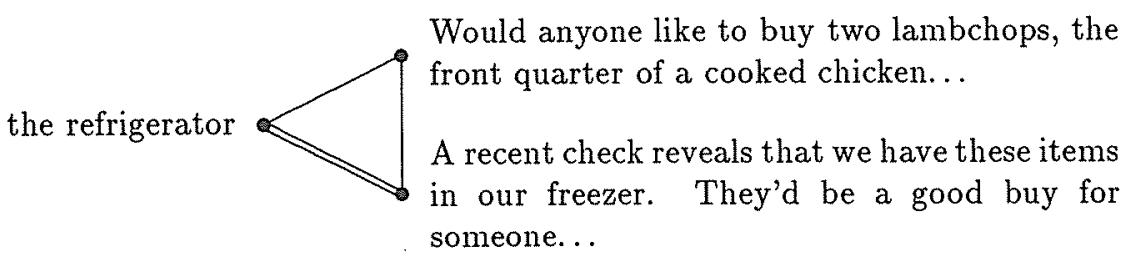

As for the single lines, the semantic relations can be described in the following way: in (92) there is no apparent connection, in (93) the two fragments are comnected through the interpretation of 'cause and effect,' and in (94) the first fragment is a 'specification' of a recent check at the outset of the second fragment. A single line between the theme and the fragment, without any direct reference to this theme, indicates the semantic 'association' of teacher and students in the school scenario in the second case and the 'specification' of the contents of the theme (refrigerator) in the third case. 


\subsection{A Complex Case: An Analogy to Multiple-Conjunct Coordinations}

Let us consider a text like the following:

(95) a. The great black and yellow rocket 46 feet long stood in the New Mexico desert. It was a huge rocket that weighed 5 tons even when empty. It was designed by a famous American physicist who lived in Washington with his family.

b. He is a really loving husband, and he and his wife always do things together. As a matter of fact, she is an able electrical engineer.

c. So she also took a very important part in this New Mexico project. Actually, she designed the orbital guidance system of the rocket.

[expanded from Beaugrande (1980:1)]

Fragment (95b) expands upon fragment (95a), and fragment (95c) expands upon fragment (95b) by developing, in both cases, a story about a referent mentioned in the previous discourse. The story starts out with 'the rocket,' then moves on to 'the scientist who designed it,' then on to 'his wife,' and finally on to 'the relation between the rocket and his wife.' This is merely an average text that one might routinely encounter. But if we fix the theme of the text to 'the rocket,' something interesting happens.

(96) QUESTION: What about the rocket?

$$
\text { ANSWER: } \quad \begin{array}{ll} 
& (95 \mathrm{a}) \\
& *(95 \mathrm{a})+(95 \mathrm{~b}) \\
& (95 \mathrm{a})+(95 \mathrm{~b})+(95 \mathrm{c})
\end{array}
$$

As the theme 'rocket' disappears from the text and is replaced by the story of 'the scientist and his wife,' the whole text comes to be unnatural as an answer to the initial question. It ceases to be simply a statement about the rocket. However, when the last two sentences, which specify the relation between the wife and the rocket itself, are introduced into the story as the concluding statement, the whole text becomes appropriate as a remark about 'the rocket.' This is just the same as in the case of the scenario-type VP conjunctions, where semantic closure is needed for the well-formedness of the whole conjunction. ${ }^{10}$

Graphically, (95) is represented as follows:

(97) $[=(95)]$

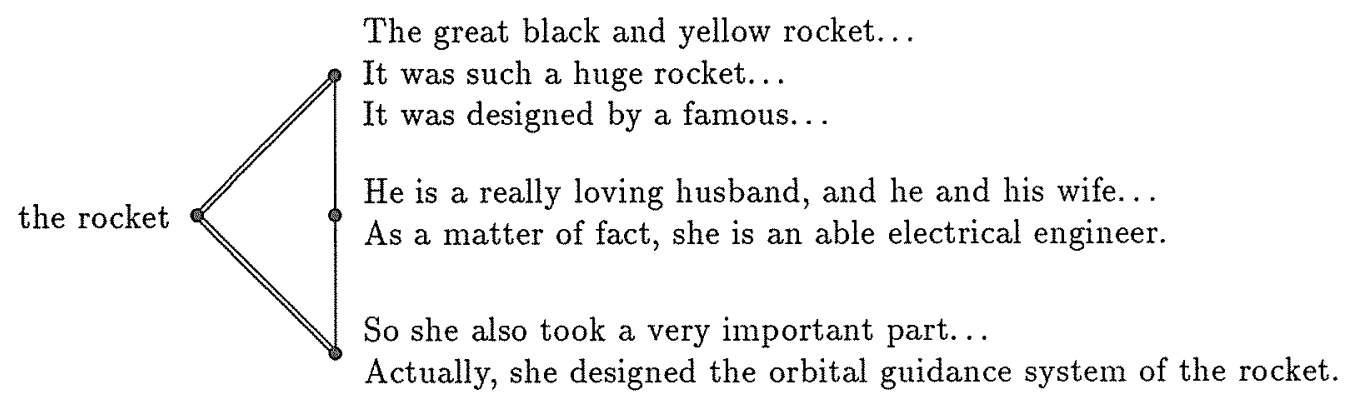

\section{SUMMARY}

We have shown, first of all, that the CSC is untenable as a syntactic constraint and should be replaced by the semantic and functional constraint developed here, that the restrictions on ATB extractions should also be reconsidered from a semantic point of view, and finally that coordinate structures within relatives form a kind of scenario describing a fixed theme, which is, of course, the antecedent. The notion of 'theme,' is often considered to be a part of the exclusive domain of discourse and text analysis, yet we have also seen that the constraints regulating the relation of

\footnotetext{
${ }^{10}$ Longacre (1979) cites data from various languages to show the importance of the beginning and the ending of a particular fragment of a text. In these places, we often find grammatical markers which signal the semantic closure of a paragraph.
} 
the antecedent with the rest of a relative, i.e., the relation between the theme and the rheme, are merely a reflection of the principles governing the formation of larger texts.

A phenomenon which was thought to be strictly sentence-internal and rigidly describable with syntactic information (that of coordinate structures within relative clauses) has now turned out to mirror phenomena found in the wider context of multisentential texts. Both sentence-formation and text-formation have the same features when observed from the communicative viewpoint of theme-rheme combination. 'This is exactly what is to be expected if one adopts a functionalist view, that of regarding a sentence as a text-fragment that keeps many of the characteristics of the enveloping textual structure. 


\section{APPENDIX 1}

The following table shows the raw results of a quantitative survey carried out with the help of two faculty members of Kobe Shoka Daigaku (Kobe University of Commerce), Ikuhiro Tamori and Hideo Tominaga. Respondants to the questionnaire were requested to rate the acceptability of sentences according to a four point scale - 0 'unacceptable,' 1 'rather unacceptable,' 2 'rather acceptable,' and 3 'acceptable.' The total number of subjects who took part in this questionnaire was 25. (As for (5a), one of the informants forgot to give an answer, so the total number of reactions is 24 in this particular case.)

\begin{tabular}{lrrrrl|lrlrrc}
\hline \hline EX. & 0 & 1 & 2 & 3 & MEAN & EX. & \multicolumn{1}{c}{0} & 1 & 2 & 3 & MEAN \\
\hline$(2 \mathrm{a})$ & 6 & 9 & 7 & 3 & 1.28 & $(9 \mathrm{f})$ & 18 & 6 & 0 & 1 & 0.36 \\
$(2 \mathrm{~b})$ & 1 & 2 & 3 & 19 & 2.60 & $(45 \mathrm{a})$ & 1 & 0 & 6 & 18 & 2.64 \\
$(3 \mathrm{a})$ & 3 & 1 & 1 & 20 & 2.52 & $(46 \mathrm{~b})$ & 2 & 2 & 5 & 16 & 2.40 \\
$(3 \mathrm{~b})$ & 5 & 5 & 6 & 9 & 1.76 & $(47 \mathrm{a})$ & 11 & 7 & 3 & 4 & 1.00 \\
$(4)$ & 5 & 7 & 7 & 6 & 1.56 & $(47 \mathrm{~b})$ & 16 & 8 & 1 & 0 & 0.40 \\
$(5 \mathrm{a})$ & 7 & 3 & 3 & 11 & 1.75 & $(48 \mathrm{a})$ & 4 & 4 & 10 & 7 & 1.80 \\
$(6)$ & 8 & 5 & 9 & 3 & 1.28 & $(48 \mathrm{~b})$ & 2 & 6 & 14 & 3 & 1.72 \\
$(7 \mathrm{a})$ & 4 & 3 & 9 & 9 & 1.92 & $(49 \mathrm{a})$ & 7 & 3 & 6 & 9 & 1.68 \\
$(7 \mathrm{~b})$ & 2 & 1 & 7 & 15 & 2.40 & $(49 \mathrm{~b})$ & 4 & 0 & 2 & 19 & 2.44 \\
$(9 \mathrm{a})$ & 25 & 0 & 0 & 0 & 0.00 & $(52)$ & 8 & 5 & 11 & 1 & 1.20 \\
$(9 \mathrm{~b})$ & 24 & 1 & 0 & 0 & 0.04 & $(64 \mathrm{a})$ & 3 & 1 & 1 & 20 & 2.52 \\
$(9 \mathrm{c})$ & 21 & 4 & 0 & 0 & 0.16 & $(64 \mathrm{~b})$ & 14 & 8 & 2 & 1 & 0.60 \\
$(9 \mathrm{~d})$ & 23 & 1 & 1 & 0 & 0.12 & $(64 \mathrm{c})$ & 21 & 3 & 1 & 0 & 0.20 \\
$(9 \mathrm{e})$ & 20 & 5 & 0 & 0 & 0.20 & $(64 \mathrm{~d})$ & 12 & 3 & 4 & 6 & 1.16 \\
\hline
\end{tabular}

All of the sentences included in the questionnaire figure in the text of this paper. They are therefore identified in the above table according to their example numbers, which are listed in the columns labeled 'Ex.' The columns marked ' 0 ' through ' 3 ' correspond to acceptability ratings: each one displays the number of respondants that indicated the rating in question. The remaining columns list means of acceptability. 


\section{APPENDIX 2}

The following table displays the statistical significance of differences in mean values for selected pairs of examples:

\begin{tabular}{lcrr|lccc}
\hline \hline \multicolumn{1}{c}{ EX's. } & DIFF. & \multicolumn{1}{c}{$t$} & \multicolumn{1}{c}{ SIG. } & \multicolumn{1}{c}{ EX's. } & DIFF. & \multicolumn{1}{c}{$t$} & SIG. \\
\hline$(2 \mathrm{a}),(9 \mathrm{a})$ & 1.28 & 6.667 & 0.001 & $(47 \mathrm{a}),(47 \mathrm{~b})$ & 0.60 & 2.433 & 0.02 \\
$(2 \mathrm{~b}),(9 \mathrm{a})$ & 2.60 & 16.250 & 0.001 & $(47 \mathrm{a}),(48 \mathrm{a})$ & 0.80 & 2.673 & 0.02 \\
$(3 \mathrm{a}),(9 \mathrm{~b})$ & 2.48 & 11.888 & 0.001 & $(47 \mathrm{a}),(48 \mathrm{~b})$ & 0.72 & 2.682 & 0.02 \\
$(3 \mathrm{~b}),(9 \mathrm{~b})$ & 1.72 & 7.427 & 0.001 & $(47 \mathrm{~b}),(49 \mathrm{a})$ & 1.28 & 4.747 & 0.001 \\
$(4),(9 \mathrm{c})$ & 1.40 & 6.234 & 0.001 & $(47 \mathrm{~b}),(49 \mathrm{~b})$ & 2.04 & 8.256 & 0.001 \\
$(5 \mathrm{a}),(9 \mathrm{~d})$ & 1.63 & 5.945 & 0.001 & $(47 \mathrm{~b}),(52)$ & 0.80 & 3.651 & 0.001 \\
$(6),(9 \mathrm{e})$ & 1.08 & 4.846 & 0.001 & $(49 \mathrm{~b}),(52)$ & 1.24 & 4.292 & 0.001 \\
$(7 \mathrm{a}),(9 \mathrm{f})$ & 1.56 & 6.198 & 0.001 & $(64 \mathrm{a}),(64 \mathrm{~b})$ & 1.92 & 7.385 & 0.001 \\
$(7 \mathrm{~b}),(9 \mathrm{f})$ & 2.04 & 9.050 & 0.001 & $(64 \mathrm{a}),(64 \mathrm{c})$ & 2.32 & 10.215 & 0.001 \\
$(45 \mathrm{a}),(46 \mathrm{~b})$ & 0.24 & 1.033 & - & $(64 \mathrm{a}),(64 \mathrm{~d})$ & 1.36 & 4.198 & 0.001 \\
$(45 \mathrm{a}),(47 \mathrm{a})$ & 1.64 & 6.345 & 0.001 & $(64 \mathrm{~b}),(64 \mathrm{c})$ & 0.40 & 2.132 & 0.05 \\
$(45 \mathrm{a}),(47 \mathrm{~b})$ & 2.24 & 12.598 & 0.001 & $(64 \mathrm{~b}),(64 \mathrm{~d})$ & 0.56 & 1.882 & - \\
$(46 \mathrm{~b}),(47 \mathrm{a})$ & 1.40 & 4.854 & 0.001 & $(64 \mathrm{c}),(64 \mathrm{~d})$ & 0.96 & 3.563 & 0.001 \\
$(46 \mathrm{~b}),(47 \mathrm{~b})$ & 2.00 & 9.129 & 0.001 & & & & \\
\hline
\end{tabular}

The columns labeled 'EX's.' list by number the examples whose mean values are being compared. The columns labeled 'DIFF.' display the mean of the first-mentioned example minus the mean of the second-mentioned example. The results of applying the $t$-test to the raw numerical scores listed in appendix 1 are shown in the columns labeled ' $t$.' The remaining columns indicate the significance of the $t$-test results. For instance, when we compare (2a) and (9a), both of which involve an extraction from a coordinate structure of sentences, we get the quantitative result of the former's being more acceptable than the latter. But it may be the case that the result is nothing more than an accident. What we need to do is to calculate the statistical probability that values identical to those of the reported results occurred accidentally. The value for $t$ indicates how far the results lie from the mean value of a random distribution. The significance is computed from $t$ to indicate the probability of the same value occuring in a random distribution. The numbers in the 'SIG.' columns are thresholds: if a set of results is significant to 0.001 , then the probability of the case in question's being an accident is no greater than one in a thousand. As the number indicating significance gets smaller, the probability becomes greater that the difference in acceptability is attributable to some factor other than a random one. If the probability of a result's being attributable to random distribution is greater than 0.05 , it is usually assumed to imply that the result is not high enough to be considered as support. Such cases are indicated with '- -' The treatment of significance in this appendix is somewhat unorthodox. Most studies choose one level of significance as a standard of rigor and then simply report whether or not a given array of data is significant with respect to that standard. Since the statistical technique employed here has been applied only very sporadically to questions of acceptability of linguistic forms, there is no consensus, to our knowledge, as to a level of significance to be accepted as a standard for the discipline. We therefore present our results in a table which indicates those places where significance may be seen to a level greater than 0.05 ; thus, our results are hopefully usable, no matter what the reader may regard as an appropriate standard. 